Test Method

\title{
Comparing damage from low-velocity impact and quasi-static indentation in automotive carbon/epoxy and glass/polyamide- 6 laminates
}

\author{
S.W.F. Spronk ${ }^{\mathrm{a}, \mathrm{b}, *}$, M. Kersemans ${ }^{\mathrm{a}}$, J.C.A. De Baerdemaeker ${ }^{\mathrm{a}, \mathrm{c}}$, F.A. Gilabert ${ }^{\mathrm{a}, \mathrm{b}}$, R.D.B. Sevenois ${ }^{\mathrm{a}, \mathrm{b}}$, \\ D. Garoz ${ }^{\mathrm{a}, \mathrm{b}}$, C. Kassapoglou ${ }^{\mathrm{c}}$, W. Van Paepegem ${ }^{\mathrm{a}}$ \\ a Department of Materials, Textiles and Chemical Engineering (MaTCh), Faculty of Engineering and Architecture, Ghent University, Tech Lane Ghent Science Park-Campus \\ A, Technologiepark-Zwijnaarde 903, B-9052 Zwijnaarde, Belgium \\ b SIM Program M3Strength, Technologiepark-Zwijnaarde 935, B-9052 Zwijnaarde, Belgium \\ ${ }^{c}$ Aerospace Structures and Computational Mechanics Group, Faculty of Aerospace Engineering, Delft University of Technology, P.O. Box 5058, 2600 GB Delft, The \\ Netherlands
}

\section{A R T I C L E I N F O}

\section{Keywords:}

Polymer-matrix composites (PMCs)

Low-velocity impact

Quasi-static indentation

Ultrasonics

Optical microscopy

\begin{abstract}
A B S T R A C T
The results of a low-velocity impact programme on both carbon/epoxy and glass/polyamide- 6 composite laminates are compared to the results of quasi-static indentation. Cross-ply and quasi-isotropic stacking sequences are impacted and quasi-static indentation tests are performed up to the same maximum displacement. The response of the laminates to both test methods is compared in terms of force-displacement behaviour, dissipated energy and resulting damage. Significant differences between low-velocity impact and quasi-static indentation are found for both material systems. It is therefore concluded that the test methods cannot be interchanged for material characterisation.
\end{abstract}

\section{Introduction}

It is important to know the damage development sequence in composites to be able to validate predictive models and create a safe vehicle design. An impact test generally has only a short duration, making it hard to tell anything about the damage sequence. Some authors turn towards quasi-static indentation (QSI) in an attempt to overcome the difficulties, e.g. Ref. [1]. Compared to low-velocity impact (LVI), QSI is much easier: low acquisition rates suffice and there is an absence of oscillations. Also, a series of tests with an increasing maximum displacement can be performed to investigate the damage sequence. The standard states that QSI can be applied to simulate the force-displacement relationships of impacts governed by boundary conditions [2]. Many composites, however, are rate-dependent [3]. Rate-dependency invalidates the use of QSI to simulate LVI, because time becomes an important factor, as noted by the standard. Some composites only show a small change of behaviour with rate, so the questions rise: how are the test results affected by material rate-dependency and can a QSI test be used to characterise impact damage for relatively rate-insensitive composites?

Two automotive composites are investigated to answer these questions: carbon/epoxy (C/E) and glass/polyamide-6 (G/PA-6). For C/E, only the matrix shows a dependency on rate, and it is expected that the results for QSI lie close to those for LVI. For G/PA-6, loading speed affects many mechanical properties significantly, and a large difference between QSI and LVI results is anticipated.

Several researchers compare QSI to LVI for C/E laminates. Some claim that both result in similar behaviour and/or equivalent damage [1,4-9]. In few of these cases, the QSI values indeed match the average LVI results $[7,9]$. In other cases, the data shows more than $10 \%$ difference in the relation between load and displacement or damage $[1,4-6,8]$.

Other authors conclude that LVI and QSI are different for C/E [10-15]. Kwon and Sankar [13] and Highsmith [12] conclude that QSI leads to a larger damage zone compared to LVI, contradicting with Lagace [14] and the results of Kaczmarek [5]. Nettles and Hodge [15] and Breen et al. [11] show results that indicate QSI leads to a more than $10 \%$ higher load compared to LVI, the opposite is seen by Abdallah et al. [10] who observe a $15 \%$ reduction in load.

Few compare both methods for composites of any thermoplastic matrix. Only sources for carbon/PEEK were found, with contradicting conclusions. Sjöblom et al. [7] conclude that QSI is equivalent to LVI, while Aymerich et al. [16] see a change in damage mechanism from delamination to fibre failure when switching to QSI. No attempt is made

\footnotetext{
* Corresponding author. Department of Materials, Textiles and Chemical Engineering (MaTCh), Faculty of Engineering and Architecture, Ghent University, Tech Lane Ghent Science Park-Campus A, Technologiepark-Zwijnaarde 903, B-9052 Zwijnaarde, Belgium.

E-mail address: siebe.spronk@ugent.be (S.W.F. Spronk).

URL: http://www.composites.ugent.be (S.W.F. Spronk).
} 
Table 1

Specimen layups and dimensions. $L, W$ and $t$ stand for length, width and thickness, respectively.

\begin{tabular}{|c|c|c|c|c|c|c|c|c|c|c|}
\hline \multirow[t]{3}{*}{ Material } & \multirow[t]{3}{*}{ Layup } & \multicolumn{3}{|c|}{ Average $[\mathrm{mm}]$} & \multicolumn{6}{|c|}{ Coefficient of variation $[\%]$} \\
\hline & & \multirow[t]{2}{*}{$\mathrm{L}$} & \multirow[t]{2}{*}{$\mathrm{W}$} & \multirow[t]{2}{*}{$\mathrm{t}$} & \multicolumn{3}{|c|}{ Max. per specimen } & \multicolumn{3}{|c|}{ Overall } \\
\hline & & & & & $\mathrm{L}$ & $\mathrm{W}$ & $\mathrm{t}$ & $\mathrm{L}$ & $\mathrm{W}$ & $\mathrm{t}$ \\
\hline $\mathrm{C} / \mathrm{E}$ & {$[0 / 90]_{6 s}$} & 149.94 & 100.00 & 5.537 & 0.08 & 0.04 & 1.49 & 0.06 & 0.02 & 0.79 \\
\hline $\mathrm{C} / \mathrm{E}$ & {$[45 / 0 /-45 / 90]_{3 s}$} & 149.96 & 100.01 & 5.537 & 0.06 & 0.03 & 1.07 & 0.03 & 0.02 & 0.74 \\
\hline G/PA6 & {$[0 / 90]_{5 s}$} & 150.01 & 100.07 & 4.748 & 0.02 & 0.15 & 1.04 & 0.03 & 0.08 & 0.6 \\
\hline G/PA6 & {$[45 / 0 /-45 / 90]_{3 s}$} & 150.06 & 100.11 & 5.882 & 0.04 & 0.19 & 1.08 & 0.02 & 0.12 & 0.72 \\
\hline
\end{tabular}

to compare LVI and QSI results from different sources, as differences in material properties, manufacturing methods, and experimental layouts easily invalidate such a comparison.

It is concluded that there is no consensus on whether QSI is equivalent to LVI or not for C/E. Moreover, often the discussion is limited to only a few aspects of the test results. Finally, to the best of the authors' knowledge, no literature exists in which LVI and QSI are compared for G/PA-6. The authors, therefore, attempt to clarify how QSI compares with LVI for the two different material systems with a broad comparison of test results.

\section{Experimental programme}

\subsection{Materials}

Two automotive composite material systems are investigated. The first is Pyrofil ${ }^{\mathrm{TM}}$ TR 360E250S carbon/epoxy. The epoxy is curing modified and cures in under $5 \mathrm{~min}$ above $140{ }^{\circ} \mathrm{C}$. The manufacturer does not disclose more information, though preliminary tests reveal a toughness close to the more tough unfilled single-phase epoxies. The supplier uses an autoclave to produce laminates with a fibre volume fraction of $60 \%$. The second composite is Cetex GA UD E-glass/polyamide- 6 with a fibre volume fraction of $47 \%$, produced using the hot press technique. Both laminates contain only unidirectional plies.

Two balanced symmetric layups are investigated per material system: cross-ply (CP) and quasi-isotropic (QI). The amount of plies is varied to reach a thickness closest to $5.0 \mathrm{~mm}$, as prescribed by the test standards $[17,2]$. Specimens of 150 by $100 \mathrm{~mm}$ are cut using a waterjet and conditioned to reduce the effect of moisture on the results. Table 1 contains the layup and dimensional details.

In hindsight, a 20-ply layup for the $\mathrm{C} / \mathrm{E} \mathrm{CP}$ would have been better. The choice was based on estimated cured ply thickness values.

\subsection{Low-velocity impact}

The authors distinguish two types of behaviour during automotive impacts: 1: mostly crushing (as part of the crumple zones in a vehicle), 2: mostly bending (as part of the safety cell). This work focuses on the second type, typically characterised by transverse out-of-plane loading. The ASTM D7136 test standard [17] seems most applicable to study this material behaviour. An in-house developed impact set-up is used to perform the dynamic experiments (Fig. 1a). It drops a $7.72 \mathrm{~kg}$ impactor onto a support structure prescribed by the standard [17] and prevents it from striking again after rebound. Data acquisition consists of the load on the 16-mm-diameter tip and the acceleration and displacement, all recorded at $1 \mathrm{MHz}$.

Three drop heights per material are selected. The lowest drop height causes a minimal amount of damage, while the highest results in widespread damage across the specimen without complete penetration. Table 2 contains an overview of all tested scenarios. Each scenario is repeated five times, resulting in 60 tests in total. The corresponding average impact energy and speed are also indicated. All scenarios fall in the category of a large-mass impact, in which the test durations are much larger than the time needed for stress waves to reach the boundaries [18]. The test are therefore appropriately termed 'low-velocity' and the plate deformation should be similar to QSI.

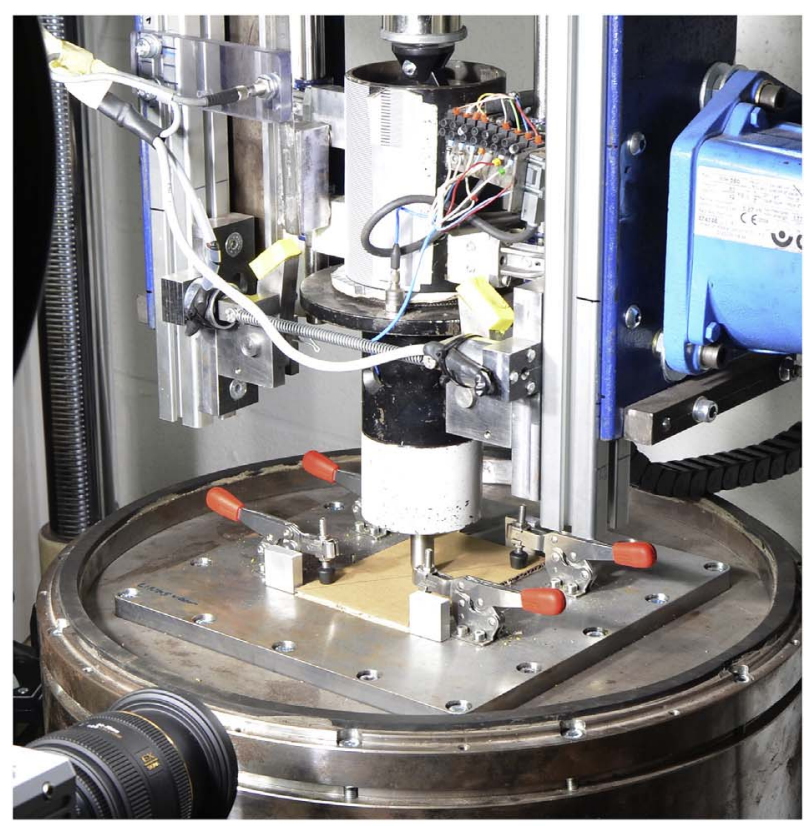

a. Bottom part of LVI set-up.

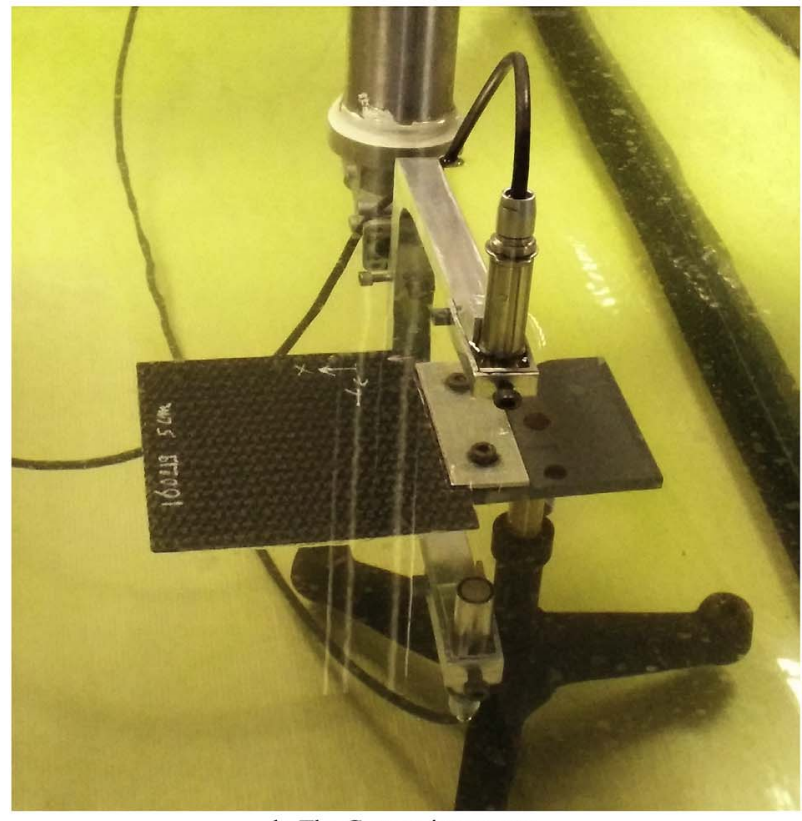

b. The C-scanning set-up.

Fig. 1. Equipment details. 
Table 2

Overview of tested scenarios in terms of material, layup and drop-height.

\begin{tabular}{|c|c|c|c|c|c|}
\hline \multirow[t]{2}{*}{ Material } & \multirow[t]{2}{*}{ Layup } & \multicolumn{4}{|c|}{ Drop height $[\mathrm{m}]$} \\
\hline & & 0.1 & 0.3 & 0.8 & 1.2 \\
\hline $\mathrm{C} / \mathrm{E}$ & $\mathrm{CP}:[0 / 90]_{6 s}$ & $\mathrm{x}$ & $\mathrm{x}$ & $\mathrm{x}$ & \\
\hline $\mathrm{C} / \mathrm{E}$ & QI: $[45 / 0 /-45 / 90]_{3 s}$ & $\mathrm{x}$ & $\mathrm{x}$ & $\mathrm{x}$ & \\
\hline G/PA6 & CP: $[0 / 90]_{5 s}$ & & $\mathrm{x}$ & $\mathrm{x}$ & $\mathrm{x}$ \\
\hline G/PA6 & QI: $[45 / 0 /-45 / 90]_{3 s}$ & & $\mathrm{x}$ & $\mathrm{x}$ & $\mathrm{x}$ \\
\hline \multirow{2}{*}{\multicolumn{2}{|c|}{$\begin{array}{l}\text { Average impact speed }[\mathrm{m} / \mathrm{s}] \text { : } \\
\text { Coefficient of variation }[\%] \text { : }\end{array}$}} & 1.3 & 2.2 & 3.4 & 4.3 \\
\hline & & 2.7 & 2.9 & 3 & 1.5 \\
\hline \multicolumn{2}{|c|}{ Average impact energy [J]: } & 6.3 & 18.5 & 44.5 & 71.1 \\
\hline \multicolumn{2}{|c|}{ Coefficient of variation $[\%]$ : } & 5.4 & 5.6 & 5.9 & 1.5 \\
\hline
\end{tabular}

\subsection{Quasi-static indentation}

The ASTM D6264 standard [2] is followed for the QSI tests. The support structure and striker tip of the impact set-up are mounted in an Instron 5800R universal testing machine, the crosshead is moved at $2 \mathrm{~mm} \mathrm{~min}^{-1}$. The displacement is measured using linear variable differential transformers (LVDTs).

Unlike the force signal, the displacement should behave smoothly and is therefore chosen to define the test end condition, as is done in e.g. Ref. [10]. For each scenario in Table 2, a representative maximum displacement is obtained which is used for QSI. Only two repetitions per scenario are carried out because of the small difference between tests of the same type, so another 24 data sets are obtained.

\subsection{Post-mortem analysis}

For each scenario, one specimen is selected for both LVI and QSI, for which the results describe best the average force-displacement behaviour of the group. These 24 specimens (12 impacted, 12 indented) are subjected to post-mortem analysis.

The damaged zone is assessed using water-coupled ultrasonic C-scans in reflection and transmission (Fig. 1b). A GE H5K transducer with diameter $13 \mathrm{~mm}$ and a GE USIP40 pulser/receiver apparatus are used to perform the scans, using ultrasonic pulses with a central frequency $f c=5 \mathrm{MHz}$. The pulser/receiver samples at a $400 \mathrm{MHz}$, evaluating the maximum pulse amplitude in the selected time gate. The distance between transducer(s) and inspected sample is approximately $70 \mathrm{~mm}$. The grid step is $1 \mathrm{~mm}$ in the transverse and $0.1 \mathrm{~mm}$ in the longitudinal direction. The scanning speed is $50 \mathrm{~mm} \mathrm{~s}^{-1}$. The water temperature is $19^{\circ} \mathrm{C} \pm 1{ }^{\circ} \mathrm{C}$.

The geometry of the dent is assessed using the pulse echo of the impacted face using the time-of-flight of the peak amplitude. This information is further employed to adapt the time gate for the C-scans in reflection to compensate for non-horizontality of the samples. Evaluation of the time-of-flight of other signal echoes yields information on the depth distribution of the delaminated area. C-scans in transmission recording provide an integrated view of damage through the depth of the specimen.

Eight C-scanned specimens are cut along their lateral and longitudinal centrelines using a precision cutting machine. The resulting planes are polished and investigated using optical microscopy.

\section{Results and discussion}

Drop height or impact energy are not applicable to QSI tests. Some authors suggest using maximum force as governing parameter of impact damage $[19,14]$. If material rate-dependency plays a role, it affects the maximum force, so it cannot be used. All curves are therefore plotted against maximum measured displacement, dynamic or quasi-static, to allow a comparison of results between test types. Note that a difference can be seen for maximum displacement between the two test methods, which is attributed to the finite stiffness of the static test bench.

\subsection{Comparing force-displacement response}

Fig. 2 contains the unfiltered results of the representative LVI tests for a drop height of $0.8 \mathrm{~m}$ together with the corresponding QSI results.

Fig. 2a and b shows that both C/E layups behave similarly for QSI and LVI, disregarding the oscillations in the dynamic results. The load increases until a sudden reduction, after which it climbs again at a reduced stiffness. The maximum load and displacement only slightly differ between LVI and QSI.

G/PA-6 shows similar behaviour for LVI and QSI until a maximum load is reached for QSI (Fig. 2c and d). QSI then shows a practically horizontal plateau until unloading, while the load of LVI climbs higher before it deviates from the initially linear behaviour. The plateau indicates that the impactor is penetrating into the material rather than continuing to deform the entire specimen. The result is a decrease in strength for G/PA-6 upon switching to QSI tests. This relates directly to the rate-dependency of 1: the strength of glass fibres [20] and 2: the flow stress and strain to failure of the PA- 6 matrix $[21,22]$. The QSI test clearly cannot represent LVI for G/PA-6, in contrast to C/E, where the difference is small. For the $\mathrm{CP}$ layup, the plateau is reached at a lower load, and also the LVI result shows a plateau.

The larger displacement of G/PA-6 CP compared to the other three is a consequence of the fact that this layup has only 20 layers instead of 24 (Table 1). Also note that, although epoxy shows rate-dependency of the Young's modulus in tension [23], the initial loading stiffness seems hardly influenced by the test type (i.e. LVI versus QSI). Further research into the strain rates during impact is needed to conclude on the expected influence of constituent rate-dependence on the impact response.

\subsubsection{Comparing force and displacement at force drop}

The C/E shows a drop in force during the loading stage for both LVI and QSI testing (circles in Fig. 2a and b), attributed to a sudden damage increase. Note that some damage is likely created before this drop which does not significantly change the bending stiffness.

The G/PA-6 does not show this behaviour. Although the LVI result for the QI laminate in Fig. 2d does show a sudden oscillation at $10 \mathrm{kN}$ where the QSI result shows a plateau, the stiffness remains practically unchanged. It is therefore uncertain whether this oscillation is related to the occurrence of damage, though several G/PA-6 QI specimens show this behaviour. There is nothing to compare the onset of the plateaus seen for QSI to, therefore this subsection focuses solely on C/E.

The force and displacement just before the load drop are plotted against maximum displacement in Fig. 3a and c for C/E CP and in Fig. 3b and d for C/E QI. Each plot shows three groups of results, corresponding to the three scenarios per laminate as outlined in Table 2. Logically, a larger maximum displacement relates to a higher drop height. The proximity of all the data points within each scenario demonstrates that the reproducibility is good. Load and displacement are almost consistently higher for LVI compared to QSI. On average, the force is $1.8 \mathrm{kN}$ higher and the displacement $0.19 \mathrm{~mm}$ more for LVI.

Note from the solid lines in Fig. 3 that the force measured just before the sudden decrease shows an increasing trend for LVI, while the displacement at this drop decreases slightly. This could indicate an increasing brittleness with rate. The values remain constant for QSI, again demonstrating the good reproducibility.

\subsubsection{Comparing maximum force and displacement}

The evolution of maximum force is plotted in Fig. 4. The average QSI result is below that for LVI for each scenario.

One could argue that the absolute difference in maximum force between QSI and LVI decreases slightly with increasing drop height for C/E (Fig. 4a and b). The difference is small though, and the QSI results 


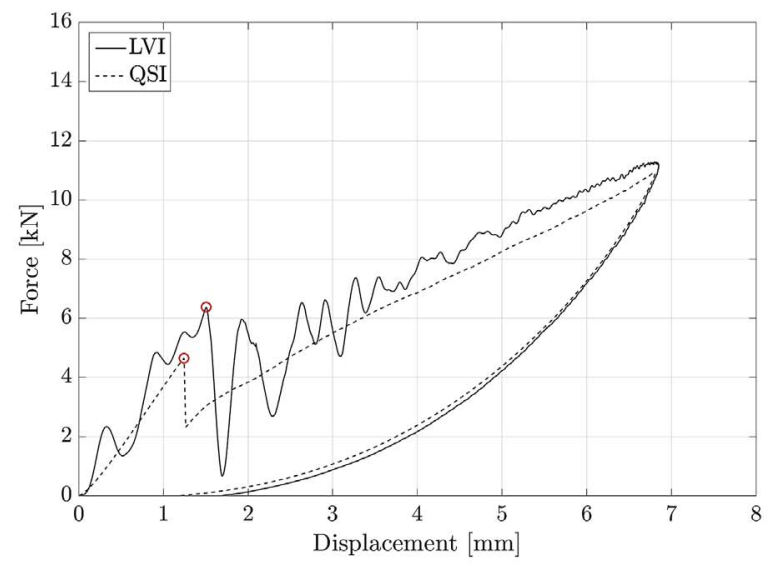

a. $\mathrm{C} / \mathrm{E} \mathrm{CP}$

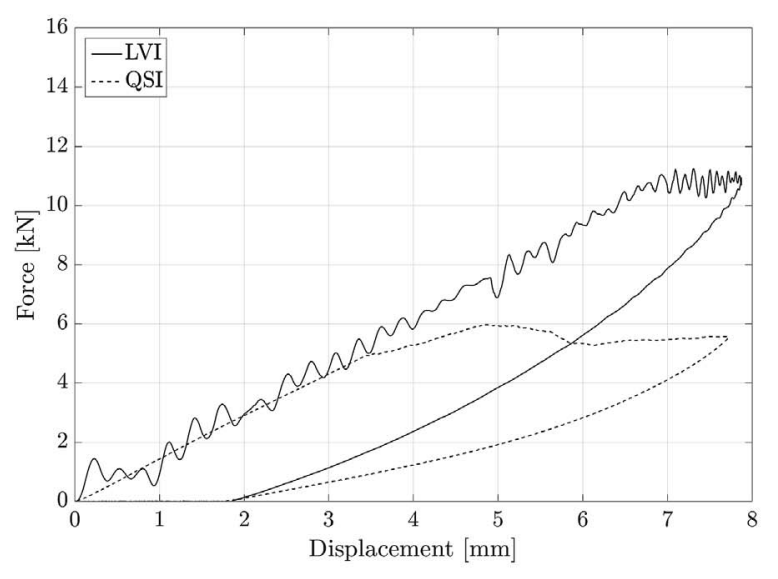

c. G/PA-6 CP

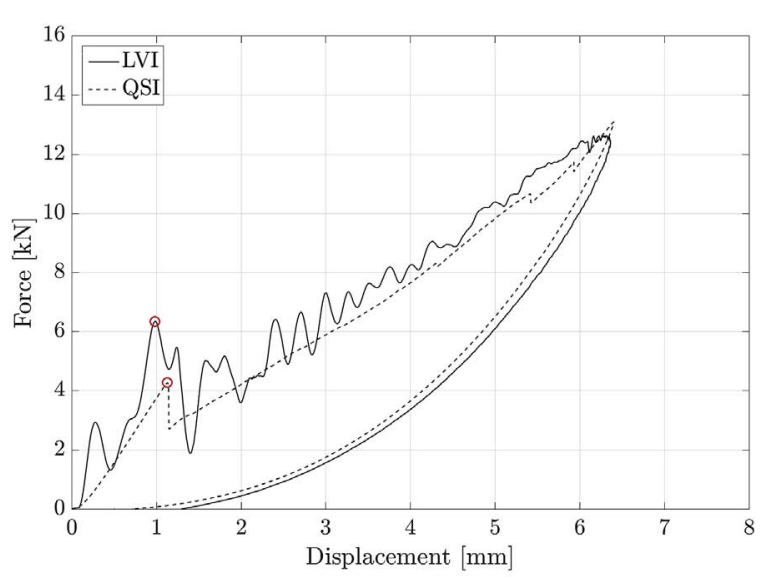

b. C/E QI

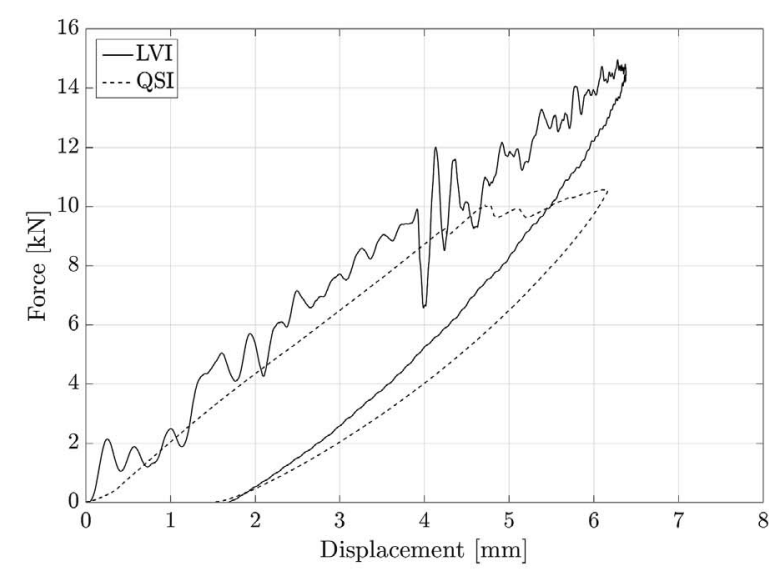

d. G/PA-6 QI

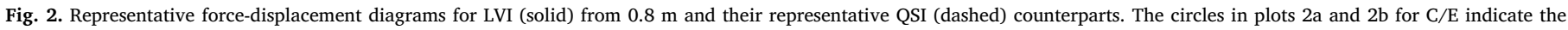
selected moments of initial load drop.

fall inside the scatter band of the LVI results at higher maximum displacement.

On the contrary, G/PA- 6 shows a clear difference between LVI and QSI (Fig. 4c and d), which increases with drop height. This trend is a result of the force plateaus during QSI. Where the LVI tests keep showing an increase in force, the QSI tests all show approximately the same maximum load.

\subsubsection{Comparing dissipated energy}

The ASTM standard prescribes that the dissipated energy during impact should be calculated by means of the loss of kinetic and potential energy with respect to the start of the impact [17]. The displacement signal suffices to calculate this loss, as the velocity for the kinetic energy is obtained by differentiation. The dissipated energy at the end of the impact is a measure of the amount of damage created in the material. The dissipated energy is plotted versus maximum displacement in Fig. 5.

For C/E, all QSI values fall within the scatter band of the LVI results (Fig. $5 \mathrm{a}$ and $\mathrm{b}$ ) and for G/PA-6 some difference can be discerned (Fig. $5 \mathrm{c}$ and d). The small differences for G/PA- 6 are deceiving: the force-displacement curves showed a large difference between QSI and LVI, and it will follow from the microscopic inspection that dissimilar damage patterns are created by both tests.

Comparing the different material systems with each other, it can be seen that C/E dissipates more energy than G/PA-6. One could question the validity of this comparison though, since the laminate thickness values are not equal. Further effort to find a suitable unit for an honest comparison is considered out of the scope of this work.

\subsection{C-scanning results}

As explained in section 2.4, ultrasound is used in three ways to perform a post-mortem inspection of the tested specimens.

\subsubsection{Transmission scanning}

The first type of C-scanning applied uses the measurement of transmitted ultrasound. Internal cavities attenuate sound and a reduction in transmission can thus indicate damage. Sound is reflected best on surfaces perpendicular to the travel direction. The technique is therefore most suited to detect delaminations. Some transmission Cscan results are shown in Fig. 6. The damage appears as a reduction of the signal strength in the centre of the specimens. The transmission equals zero outside the specimen because an unobstructed signal is set to fall outside the measurement range.

Fig. 6a contains the C-scan for QI C/E after LVI from $0.3 \mathrm{~m}$. There is a large damaged area which approaches the boundaries in the width direction. The impact site itself seems to block less ultrasound than its immediate surrounding, see the insert, indicating less delamination right underneath the impactor. Fig. 6b contains the result for the corresponding QSI sample, which shows a slightly larger damage zone.

Fig. $6 c$ contains the C-scan for CP G/PA-6 after LVI from $1.2 \mathrm{~m}$. The damage is confined to a relatively small zone around the impactor. The corresponding QSI specimen in Fig. 6d shows a smaller damaged area.

The transmission scans are used to compute the integrated damaged area. A transmission power reduction to $62 \%$ of the undamaged reference value is selected to consider a scanning point delaminated. This specific value correctly retrieves the scanned size of the clamp in the 


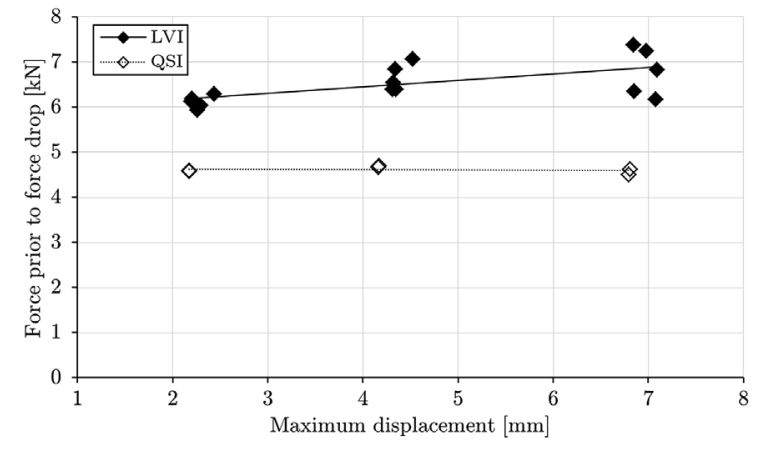

a. C/E CP: force at force drop

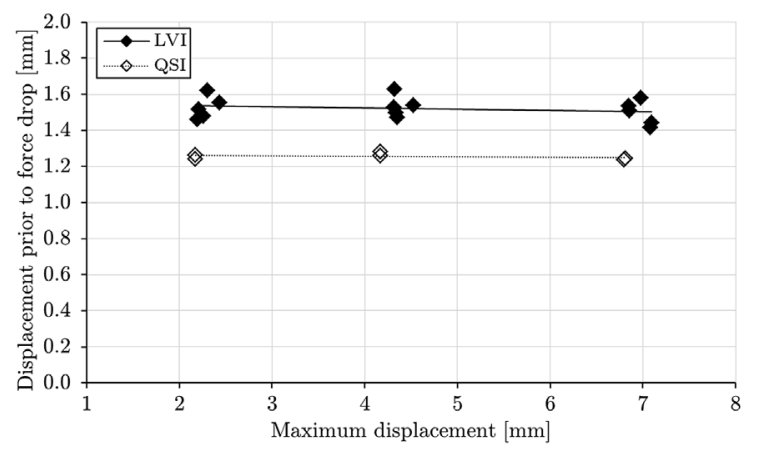

c. C/E CP: displacement at force drop

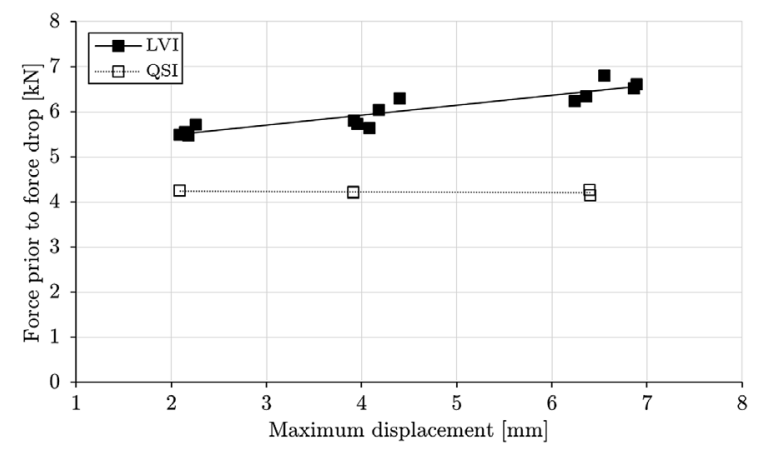

b. C/E Ql: force at force drop

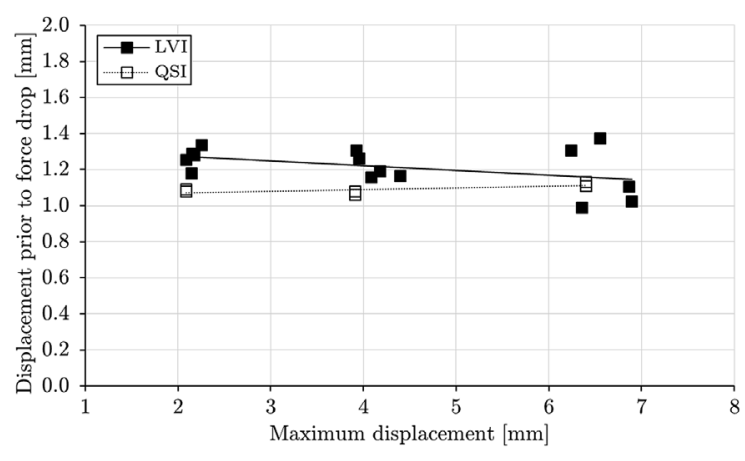

d. C/E QI: displacement at force drop

Fig. 3. Force (top) and displacement (bottom) for C/E just before the force drop, versus maximum displacement. See also the circles in Figs. $2 \mathrm{a}$ and $2 \mathrm{~b}$.

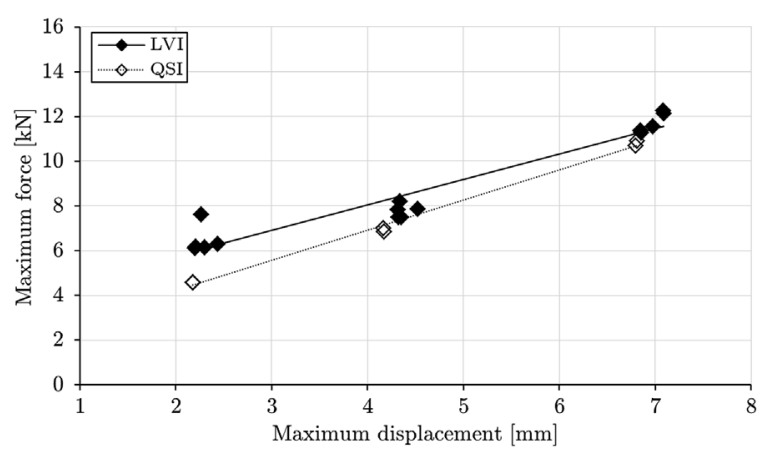

a. C/E CP

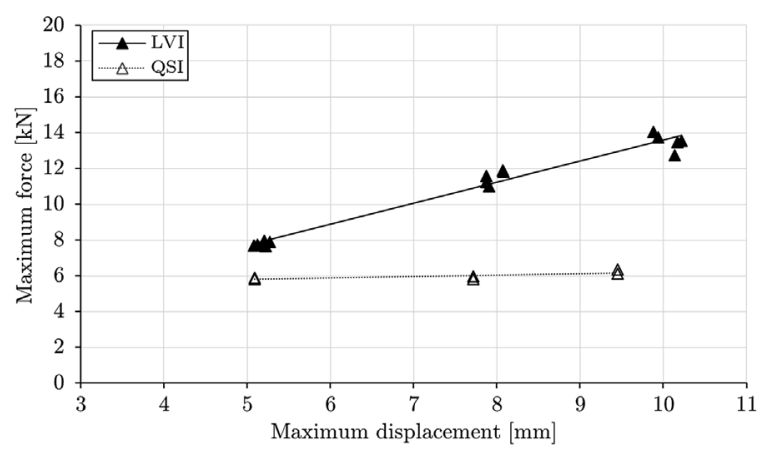

c. G/PA-6 CP

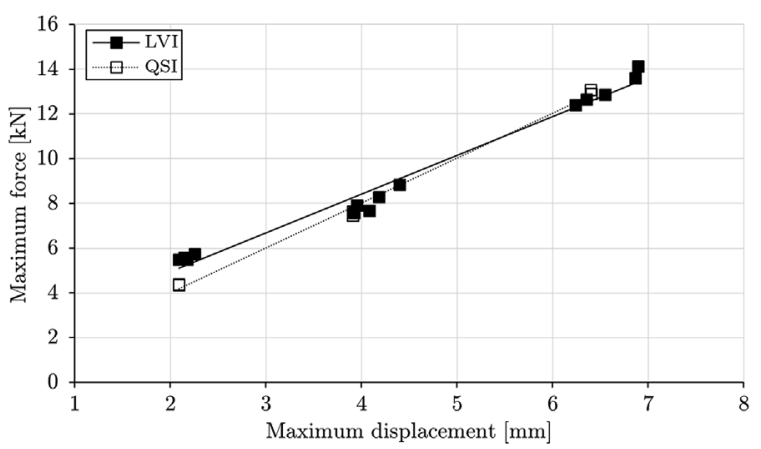

b. C/E QI

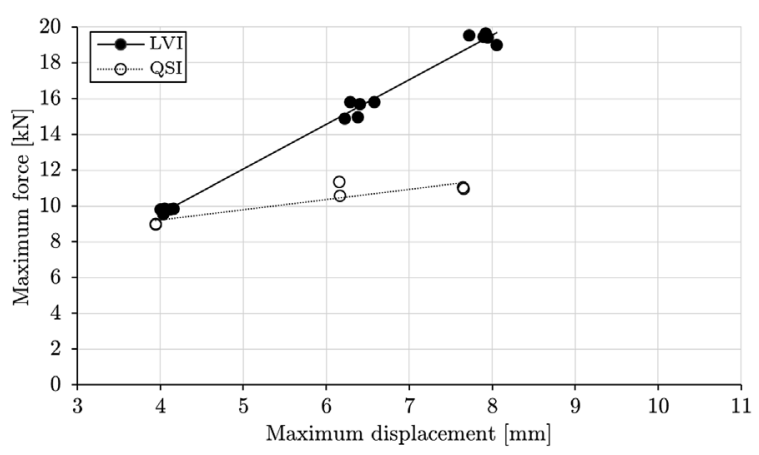

d. G/PA-6 Q

Fig. 4. Maximum force results versus maximum displacement for the four investigated composite layups. 


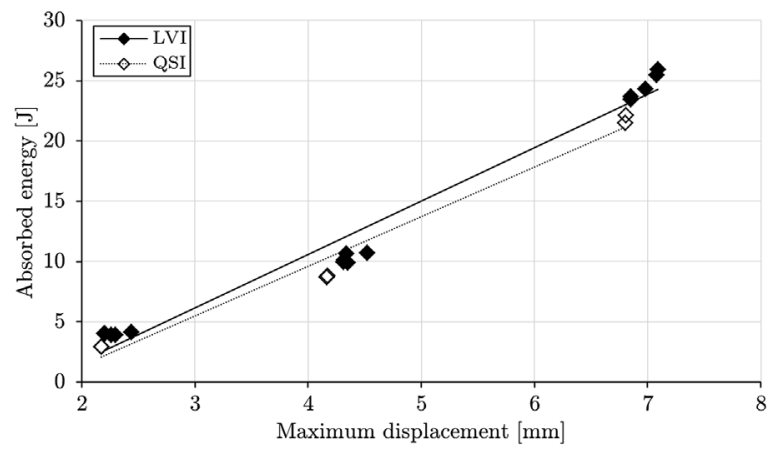

a. C/E CP

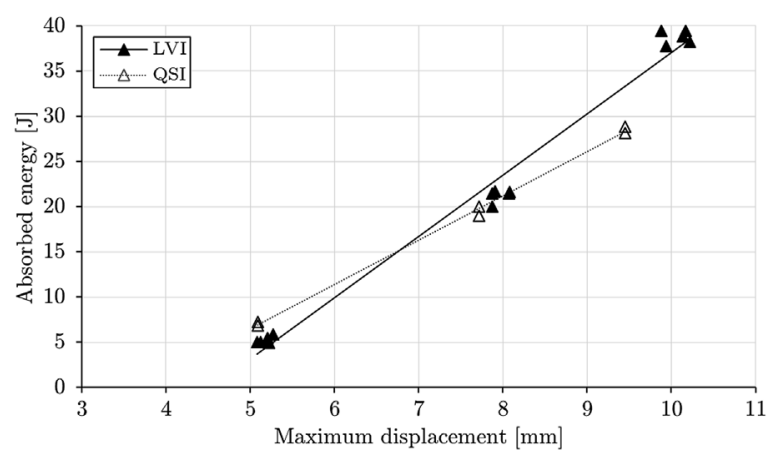

c. G/PA-6 CP

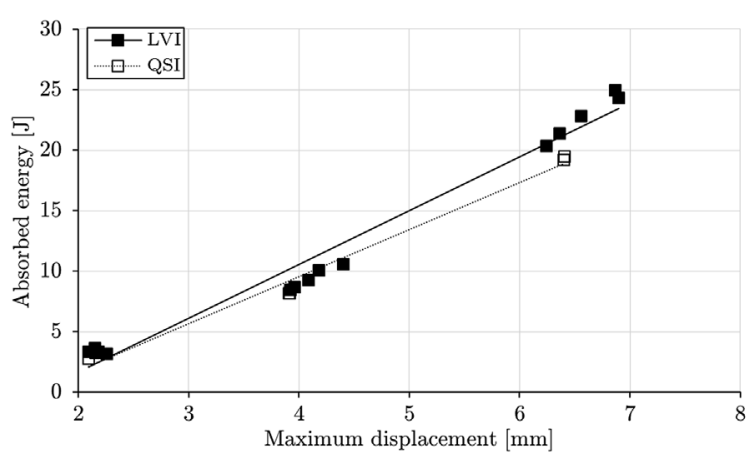

b. $C / E Q \mid$

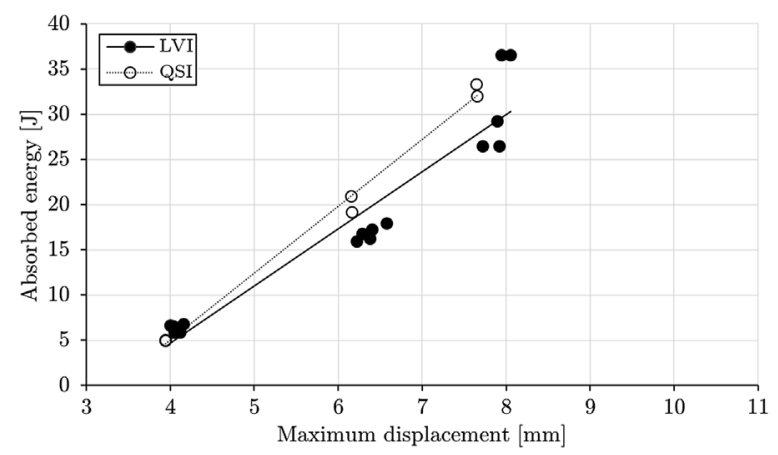

d. G/PA-6 QI

Fig. 5. Dissipated energy versus maximum displacement for the four investigated composite lay-ups.

bottom of the scans.

The calculated damage areas are set out against the maximum displacement in Fig. 7. For C/E, QSI consistently results in an approximately $650 \mathrm{~mm}^{2}$ larger damaged area compared to LVI (Fig. 7a). Section 3.1.3 concludes at the energy dissipation is equal, indicating a stronger presence of another dissipating mechanism, e.g. fibre or matrix cracking. The damage area is slightly larger for QI compared to $\mathrm{CP}$ laminates.

G/PA-6 shows a different behaviour (Fig. 7b): the damaged area after QSI is consistently about $250 \mathrm{~mm}^{2}$ below that after LVI. The QSI tests result in a more localized damage, matching the conclusion drawn in section 3.1.2 based on the plateaus in the force response.

Upon comparing the two materials with each other, the difference in area between the two material systems is striking: both plots in Fig. 7 differ by an order of magnitude. This is the reason that the scans for $\mathrm{G} /$ PA-6 are for a drop height of $1.2 \mathrm{~m}$ while those for C/E are for $0.3 \mathrm{~m}$. Still the C/E shows a larger damage size, it is much more prone to delamination than G/PA-6. Finally, the damage area for CP is consistently smaller than that for QI.

\subsubsection{Internal reflection scanning}

The internal damage can be visualised in three dimensions by operating the C-scanning system in pulse echo mode, see Fig. 8. The colour indicates the depth of reflection calculated through time-offlight, undamaged parts are set at the depth of the surface facing the transducer.

Looking at the QI C/E specimen in Fig. 8a, delaminations in different planes follow a staircase-like pattern around the impact zone in a point symmetrical fashion. The deeper delaminations seem not to run further inward than the outer edge of a more shallow delamination. This is a shadowing effect, caused by the nearly full reflection of ultrasound at a delamination. Scanning from both sides can partially resolve this issue, see Fig. 9. The deeper delaminations indeed reach further inward than the outer edge of others closer to the top surface, although again they are obscured at the centre. It appears the largest delaminations are not closest to the bottom: they do not follow a conical shape through the thickness.

Comparing the result of QI C/E after QSI (Fig. 9a) with that after LVI (Fig. 8a), one can see that the shape of the damaged regions look alike, indicating that the damage mechanisms are similar as well. The same can be concluded for CP laminates.

As mentioned before, only delaminations reflect a significant amount of ultrasound back to the emitting transducer. These thus abundantly exist in the $\mathrm{C} / \mathrm{E}$ specimens. The situation is different for $\mathrm{G} /$ PA-6 (Fig. 8b). Typically the scans show no clear reflection for any depth, suggesting that only a very small amount of delamination is present. Micro-graphic analysis shows more fibre waviness and layer thickness variations for G/PA- 6 than for $\mathrm{C} / \mathrm{E}$, compare also the differences in reflection for the undamaged material in Fig. $8 \mathrm{~b}$ and $\mathrm{a}$. Moreover, PA- 6 is expected to show a stronger ultrasound damping compared to epoxy. Both effects hinder the reflection of ultrasound.

\subsubsection{Surface reflection scanning}

The surface reflection is used to determine the dent profile after the test, Fig. 10 contains an example. The vertical axis is scaled to emphasize the differences in distance, though this also overdraws the nonhorizontality and curvature of the specimen.

The ASTM D7136 test standard defines the dent depth as the maximum distance in a direction normal to the face of the specimen from the lowest point in the dent to the plane of the impacted surface that is undisturbed by the dent [17]. The authors define the 'undisturbed surface' as the curved surface resulting from the two-dimensional linear interpolation of the elevation of the edges of the scan. The largest difference in elevation between this surface and the measurements is taken as the dent depth. The error due to non-horizontality is negligible because the alignment is within $0.66^{\circ}$. 


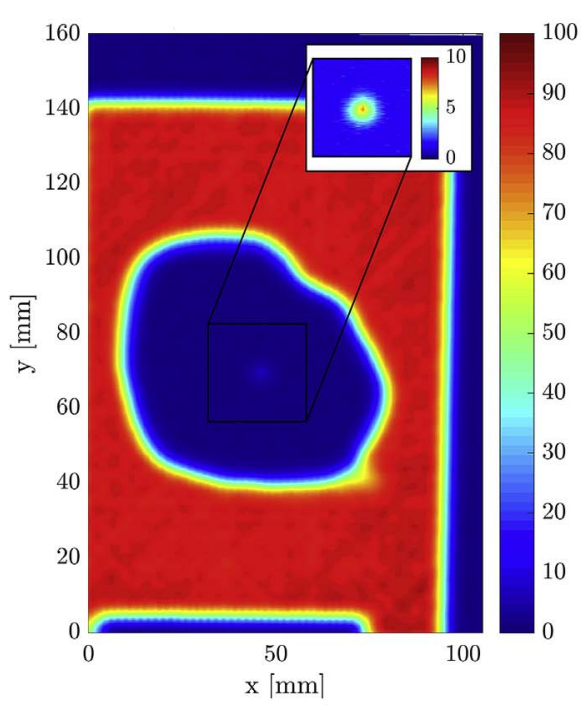

a. C/E QI LVI $0.3 \mathrm{~m}$

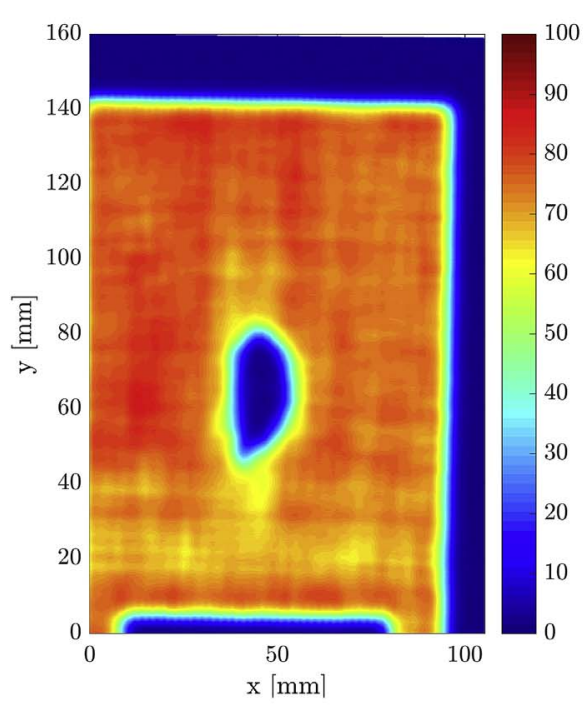

c. G/PA-6 CP LVI $1.2 \mathrm{~m}$

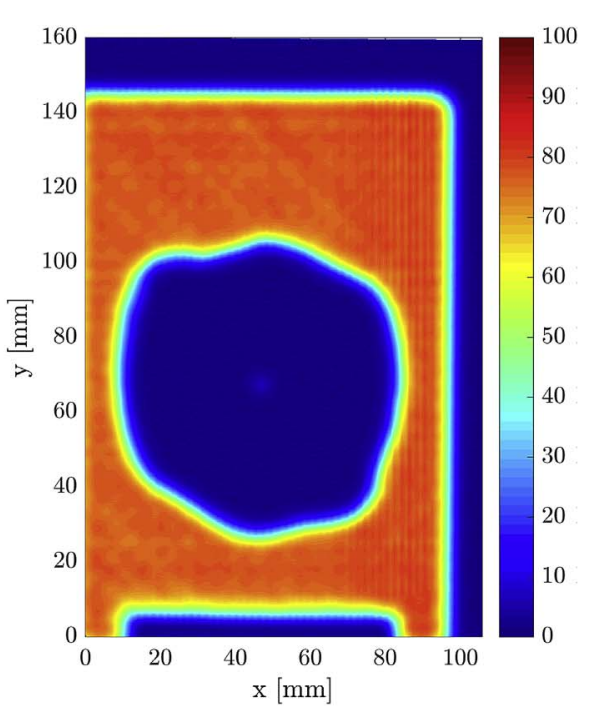

b. C/E QI QSI $0.3 \mathrm{~m}$

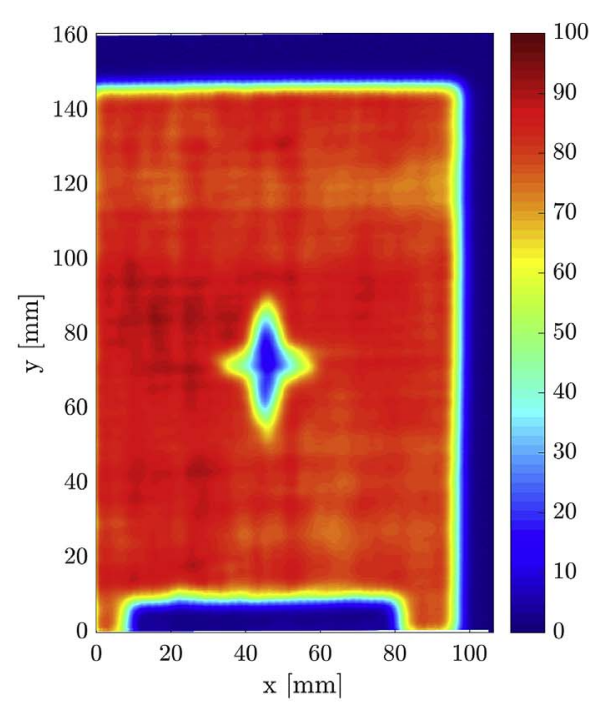

d. G/PA-6 CP QSI $1.2 \mathrm{~m}$
Fig. 6. Transmission ultrasound scans. The colours show the transmission signal strength normalised to the reference strength outside the damaged zone. The height next to QSI specimens is the drop height of the corresponding LVI specimens. The insert of figure $6 \mathrm{a}$ shows the centre section at a different colour scale.
The calculated dent depths are plotted against the maximum displacement in Fig. 11. All dent depths increase with increasing maximum displacement. QSI consistently shows a higher dent depth than LVI, with an average difference of $0.07 \mathrm{~mm}$ for C/E (or $56 \%$, see also Fig. 11a) and $0.53 \mathrm{~mm}$ for G/PA-6 (or 339\%, Fig. 11b). The depths are also larger for the $\mathrm{CP}$ than for the QI laminates.

Comparing the G/PA- 6 dent depth trends with those for the damage size in Fig. 7b, once again the change in damage mechanism between QSI and LVI becomes clear. While the damage size for QSI is smaller than for LVI, the dent depth is larger, proving that something different is happening there. For C/E CP and G/PA-6 QI the difference in depth between QSI and LVI is increasing with maximum displacement, for which there is no current explanation.

\subsection{Optical microscopy}

A micrograph of the transverse cross section of a CP C/E specimen after QSI is given in Fig. 12. The damage features have been manually identified, see Fig. 13, which also shows the corresponding LVI specimen. The identification is done for only four of the available images, because of a restriction in time. The geometry is indicated in black, damage in various colours. The arrowhead indicates the point of impact/indentation.

The end of the delaminations away from the impact zone show a large similarity for both test methods. In both cases, it can be verified that the delamination lengths increase from the top interface towards three-fourths of the depth, after which some smaller delaminations follow. These conclusions are supported by the pulse echo C-scanning in section 3.2.2.

The damage patterns also show differences which are larger than can be simply attributed to scatter in local properties. The delaminations continue underneath the impact zone for the impacted specimen, while this is practically not the case for the indented specimen, again in line with the C-scans in section 3.2.1. Another remarkable difference is a severe concentration of matrix cracks just aside of the impact for LVI, against a more even distribution of fewer matrix cracks QSI. Energy dissipation for LVI is more matrix-cracking-dominated, which also agrees with the earlier conclusion (section 3.2.1). The differences are not as striking as for G/PA-6. Still, the authors conclude they are too big to be considered negligible, especially if one intends to validate the damage predicted by high-fidelity numerical models.

The damage features of QI G/PA-6 after LVI from $1.2 \mathrm{~m}$ and its QSI 


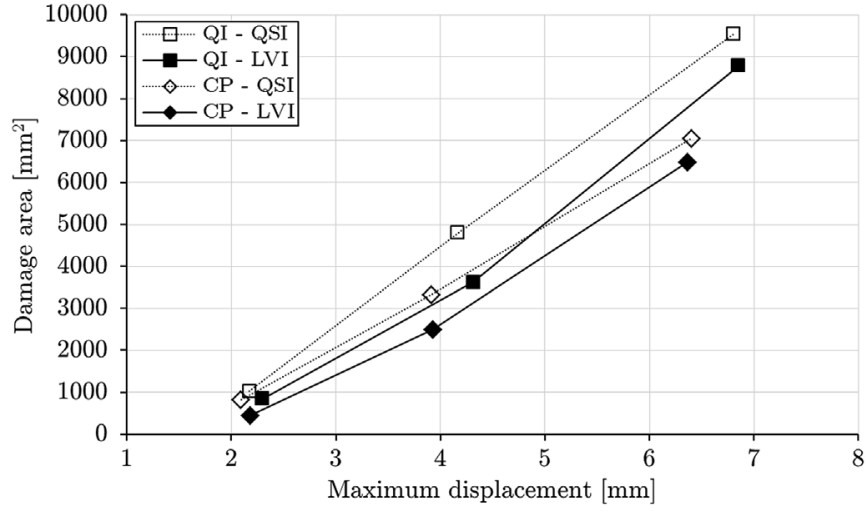

a. C/E

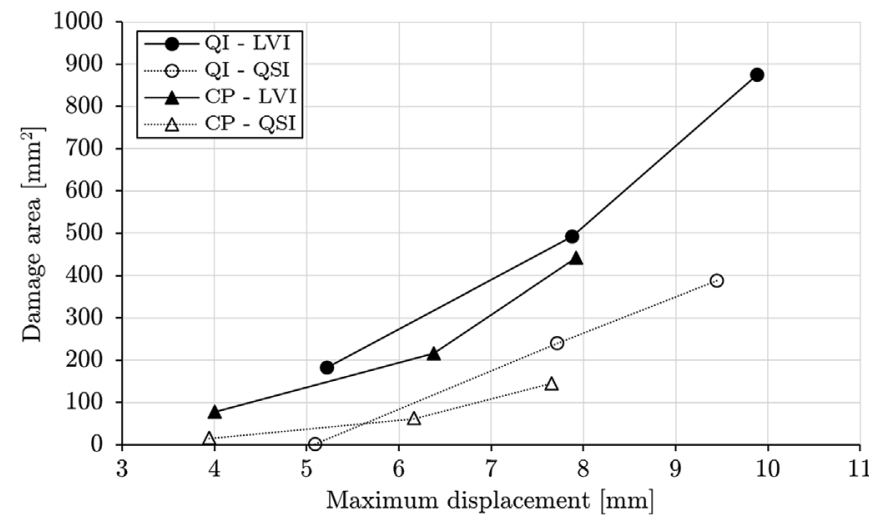

b. G/PA-6

Fig. 7. Damaged area versus maximum displacement.

counterpart are shown in Fig. 14. There is a large difference in the damage. The impacted specimen shows widespread matrix cracking in its bottom half. Some delaminations are present, mostly in the top half and close to the impact zone. The indented specimen shows few matrix cracks and delaminations, implying that PA- 6 has a higher ductility at low deformation rates. Instead of the matrix cracks and delaminations, there is severe damage underneath the indenter tip. It becomes clear that QSI cannot be used at all to characterise impact damage for this material.

The different damage mechanisms for QSI and LVI on QI G/PA-6 demonstrates the misleading character of the energy absorption plot in Fig. 5d. The plot shows an almost equal energy absorption for both methods, which could lead to false conclusions when basing on dissipated energy alone.

An interesting feature of the G-PA-6 LVI specimen is the large horizontal crack just above the middle, which is indicated with an arrow. It consists of a delamination which for a large part travels within a layer rather than at its interface. This proves that the fibre-matrix adhesion as strong as the matrix itself, explaining the small amount of delamination in the G/PA- 6 specimens.

Finally, optical microscopy is used to validate in-plane damage dimensions found along the lateral and longitudinal centrelines using Cscanning. On average, the absolute difference between optical and ultrasound delamination length is $2.5 \mathrm{~mm}$. The values are close, so the threshold value mentioned in section 3.2.1 is a relatively good choice.

\section{Conclusion}

The difference in response and post-test damage has been evaluated for carbon/epoxy and glass/polyamide- 6 composites. Cross-ply and quasi-isotropic layups were investigated. A total of 60 impact tests from four drop heights (three per material system) have been carried out,

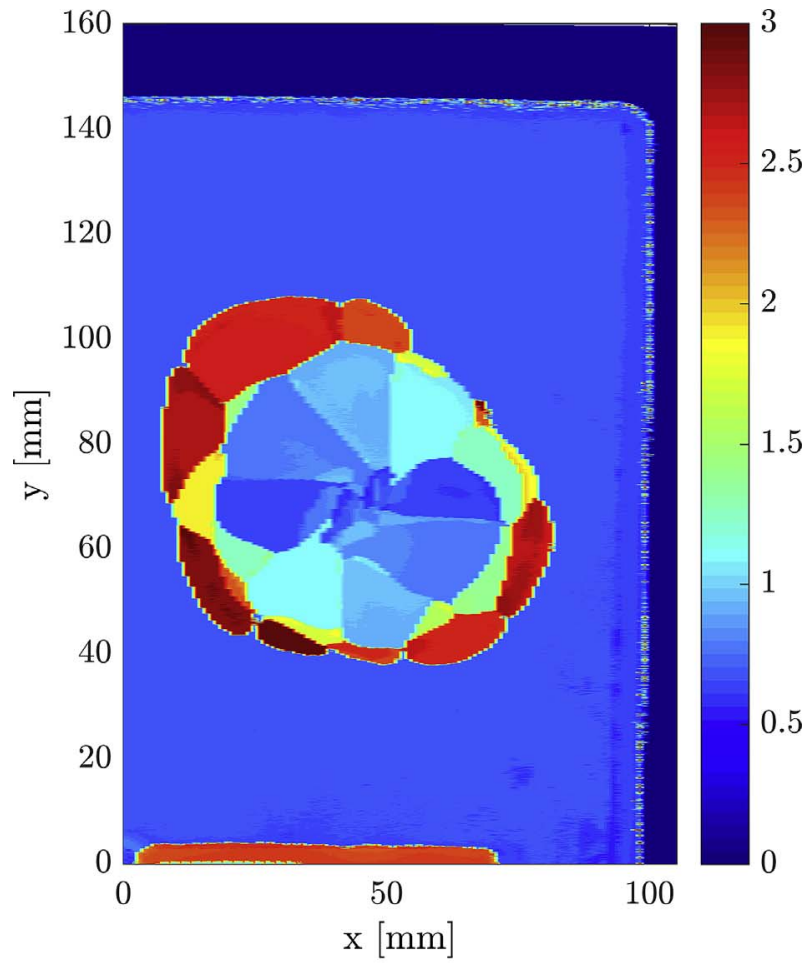

a. C/E QI LVI $0.3 \mathrm{~m}$ (see also figure 6a)

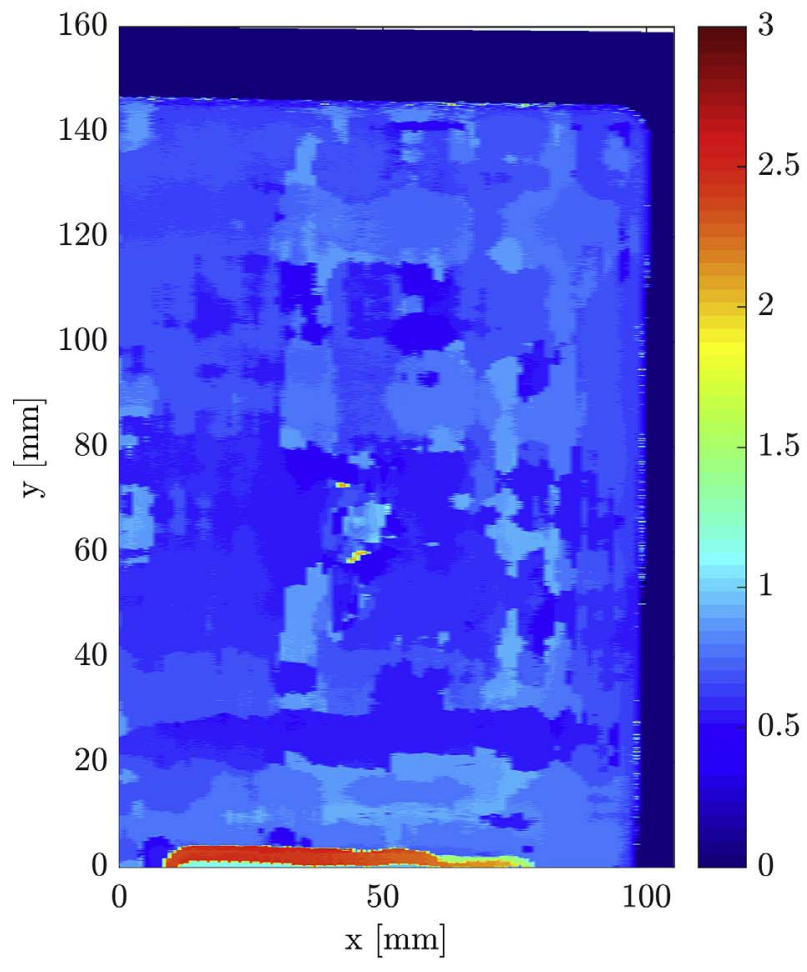

b. G/PA-6 CP LVI $1.2 \mathrm{~m}$ (see also figure 6c)

Fig. 8. Reflection C-scans of the same LVI specimens as in Fig. 6. The colours indicate the time-of-flight in $\mu$ s, a larger value thus corresponds to a deeper delamination.

accompanied by 24 quasi-static indentation tests up to the same maximum displacements. Three different C-scanning techniques and microscopy were used to investigate the type and extent of damage caused.

For glass/polyamide-6, the influence of the constituent rate- 


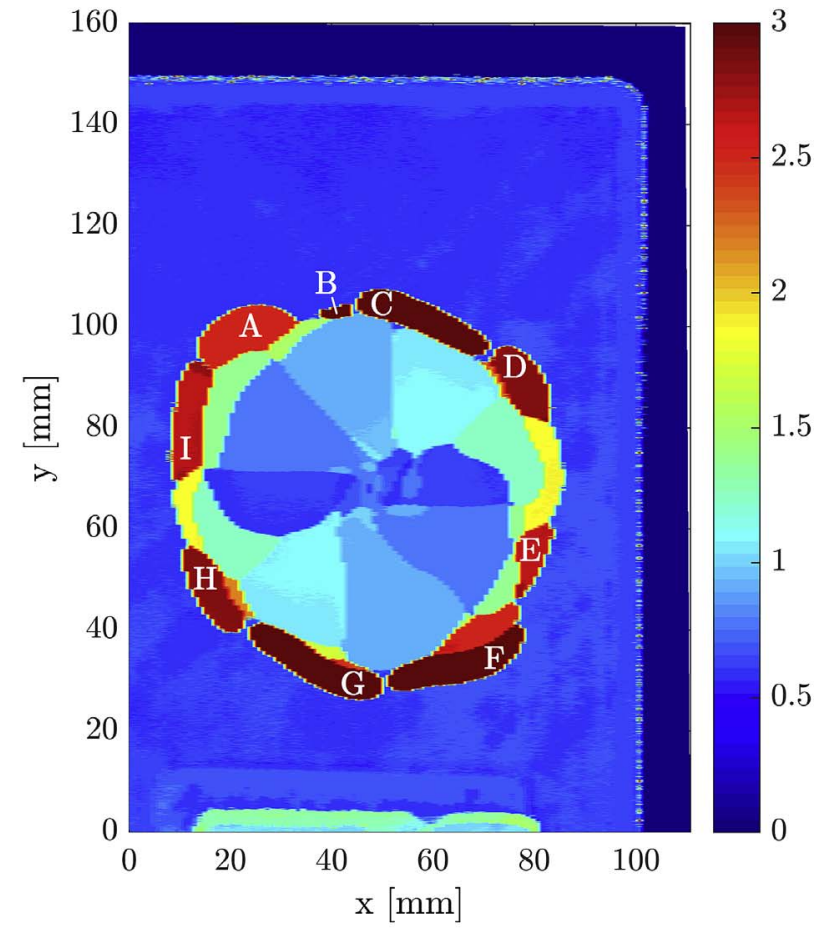

a. C/E QI QSI $0.3 \mathrm{~m}$, scanned from the top

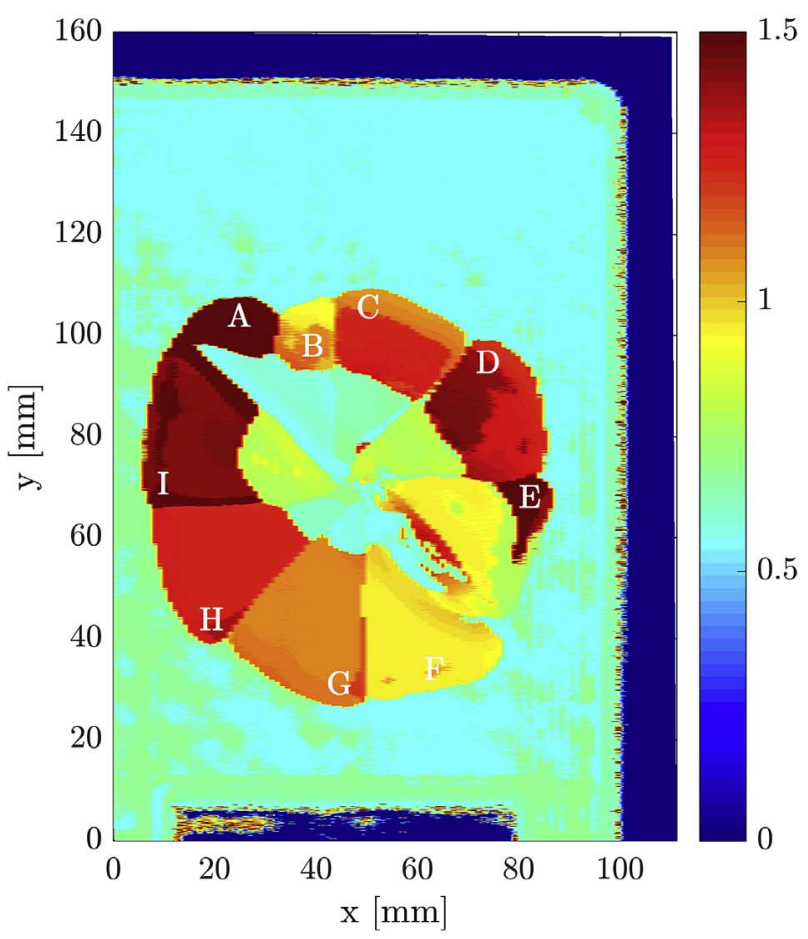

b. C/E QI QSI $0.3 \mathrm{~m}$, scanned from the bottom

Fig. 9. Reflection C-scans of QSI QI C/E (Fig. 6b) from both sides of the specimen. The colours indicate the time-of-flight in $\mu$ s. Specimen orientations are equal, so the delaminations are located in the same positions in each figure. For clarity, delaminations visible in both scans have been indicated with a letter. The mentioned height is the drop height of the LVI equivalent.

dependency on the out-of-plane behaviour is too large to be able to characterise low-velocity impact behaviour using quasi-static indentation. The force-displacement response is completely different at the higher displacement values. Other characteristics (dissipated energy, area of delamination, dent depth) are relatively similar and could lead

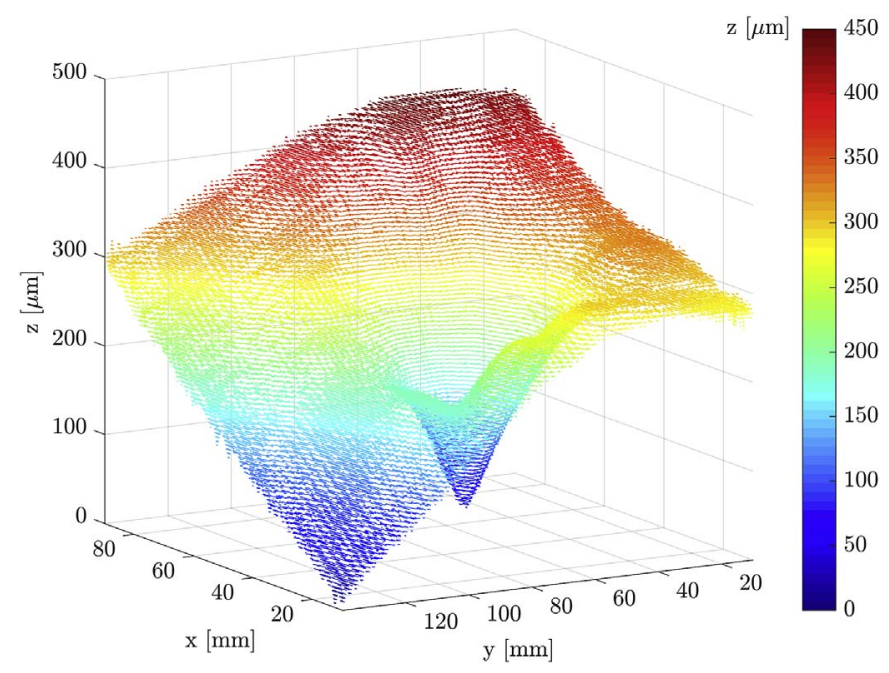

Fig. 10. Surface reflection scan of QI C/E after LVI from 0.8 meter. Notice the different scale on the z-axis compared to the in-plane axes. The colour indicates the elevation in $\mu \mathrm{m}$.

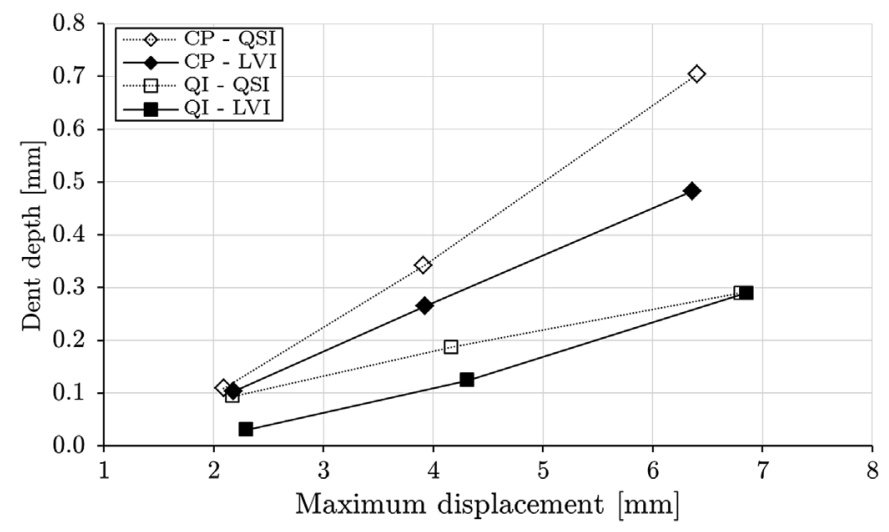

a. C/E

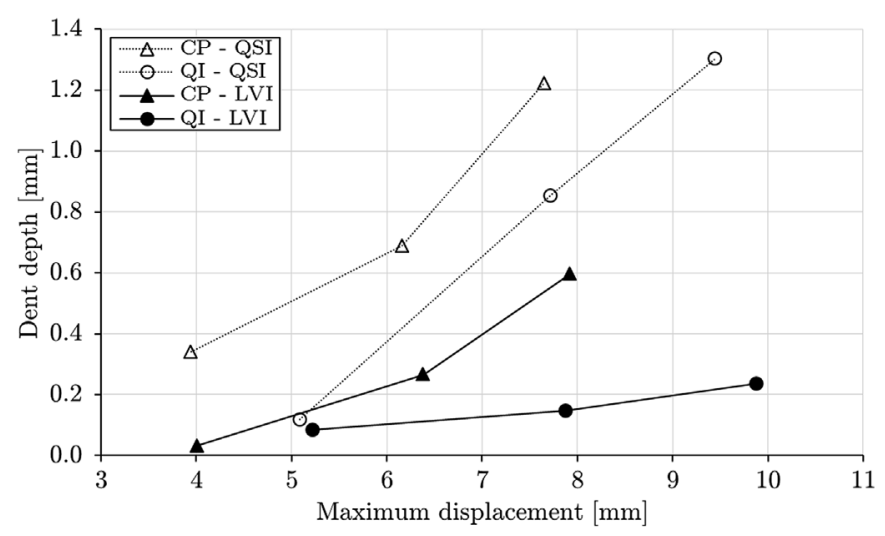

b. G/PA-6

Fig. 11. Dent depth versus maximum displacement for both material systems.

to a false sense of equivalence between the two tests. Optical microscopy brings the different damage mechanism clearly to light. The higher strength and strain to failure at high strain rate cause a much larger area to cooperate in the energy dissipation during impact by widespread matrix cracking, in contrast to the local damage zone created by indentation.

The results show, perhaps surprisingly, that carbon/epoxy also behaves significantly different in quasi-static indentation compared to 


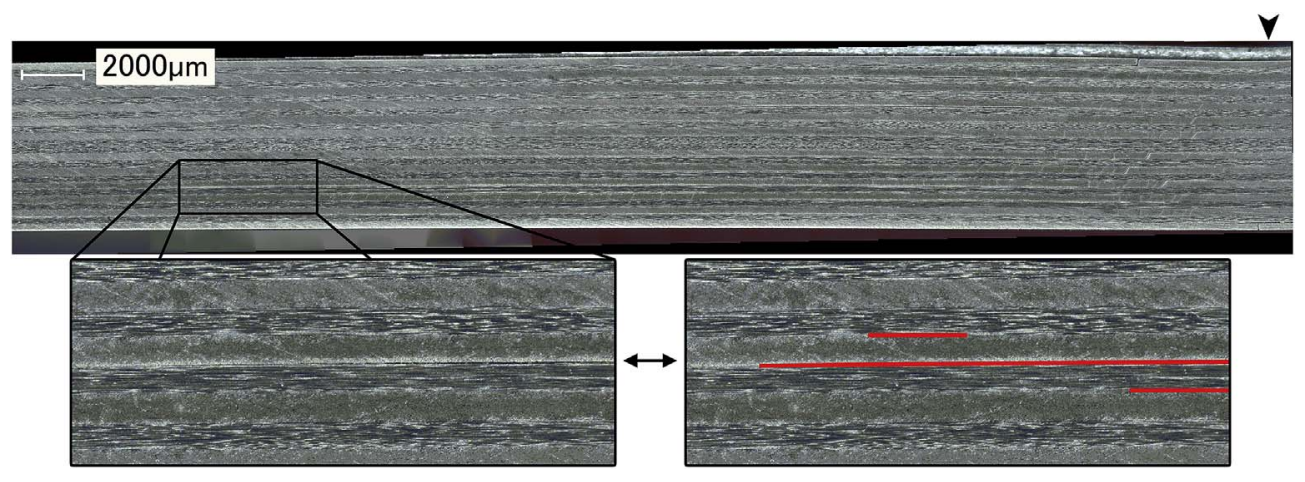

Fig. 12. Stitched micrograph of a CP C/E specimen after QSI. The indentor pushed down close to the right side of the figure, indicated with an arrowhead. Zoomed section shows the tip of the delamination, delaminations indicated in the picture on the right.
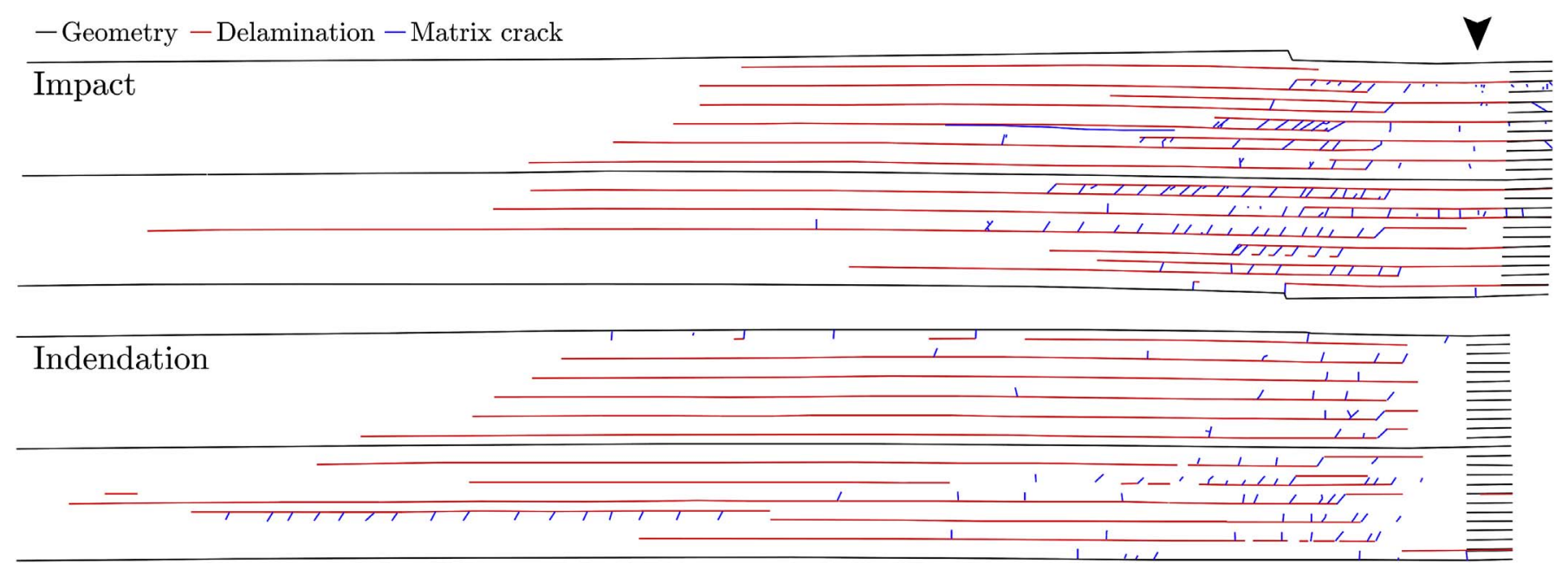

Fig. 13. Damage characterized from stitched micrographs of CP C/E after LVI from $0.3 \mathrm{~m}$ (top) and its corresponding QSI specimen (bottom, see also Fig. 12). Both images are set to the same scale andaligned at impact, indicated with an arrowhead.

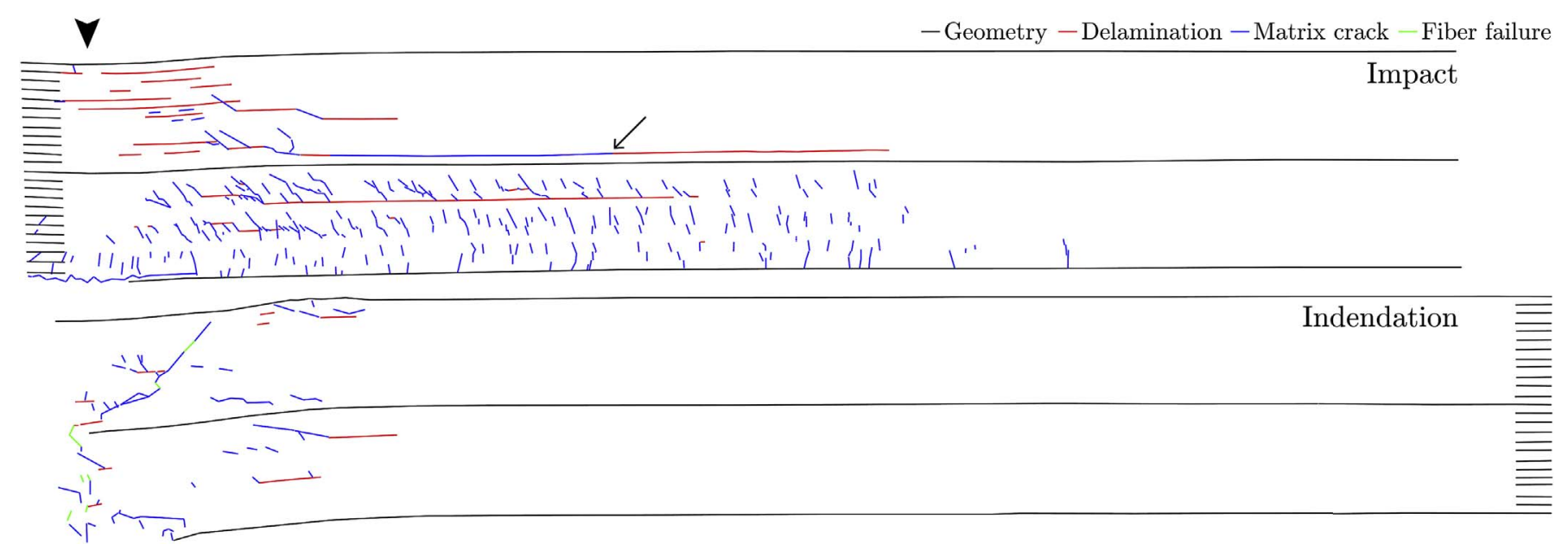

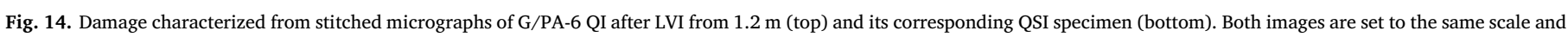
aligned at impact, indicated with an arrowhead. The arrow points to a delamination that connects to an in-plane matrix crack.

low-velocity impact. The differences are considerably smaller than for glass/polyamide-6. The force-displacement curves show an average underestimation of the load prior to the first significant stiffness loss by $1.8 \mathrm{kN}$ for quasi-static indentation. Maximum force and (again) dissipated energy are hardly affected. The C-scans show that the damaged area is overestimated on average by $650 \mathrm{~mm}^{2}$ and the dent depth by $56 \%$ when using quasi-static indentation. Optical microscopy reveals that quasi-static indentation creates virtually no damage directly underneath the impactor, contrary to low-velocity impact, and a reduced concentration of matrix cracks is seen.
Even the limited rate-dependency of the carbon/epoxy is responsible for significant differences between the results of quasi-static indentation and low-velocity impact. The authors conclude that the quasi-static indentation test is not a suitable substitute for low-velocity impact to produce accurate quantitative data about the impact performance of the two composite material systems investigated.

\section{Acknowledgements}

This work was supported by the SBO project M3Strength, which fits 
in the MacroModelMat (M3) research program funded by SIM (Strategic Initiative Materials in Flanders) and VLAIO (Flemish government agency for Innovation and Entrepeneurship). The authors express their gratitude towards Honda R\&D Co., Ltd., Mitsubishi Rayon Co., Ltd., and Ten Cate Advanced Composites B.V. for their generosity in supplying materials for this research. M. Kersemans acknowledges the financial support of Bijzonder OnderzoeksFonds (BOF) [grant number BOF.DPO.2015.0028.01].

\section{References}

[1] Y. Aoki, H. Suemasu, T. Ishikawa, Damage propagation in CFRP laminates subjected to low velocity impact and static indentation, Adv. Compos. Mater. 16 (1) (Jan. 2007) 45-61.

[2] ASTM International ASTM standard D6264, Standard Test Method for Measuring the Damage Resistance of a Fiber-reinforced Polymer-matrix Composite to a Concentrated Quasi-static Indentation Force, Technical report (2012) West Conshohocken, PA, 2012.

[3] G.C. Jacob, J.M. Starbuck, J.F. Fellers, S. Simunovic, R.G. Boeman, Strain rate effects on the mechanical properties of polymer composite materials, J. Appl. Polym. Sci. 94 (1) (2004) 296-301.

[4] G. Belingardi, R. Vadori, Influence of the laminate thickness in low velocity impact behavior of composite material plate, Compos. Struct. 61 (1-2) (July 2003) 27-38.

[5] H. Kaczmarek, S. Maison, Comparative ultrasonic analysis of damage in CFRP under static indentation and low-velocity impact, Compos. Sci. Technol. 51 (1) (Jan. 1994) 11-26.

[6] S.M. Lee, P. Zahuta, Instrumented impact and static indentation of composites, J. Compos. Mater. 25 (2) (1991) 204-222.

[7] P.O. Sjöblom, J.T. Hartness, T.M. Cordell, On Low-Velocity impact testing of composite materials, J. Compos. Mater. 22 (1) (Jan. 1988) 30-52.

[8] D.D. Symons, Characterisation of indentation damage in 0/90 lay-up t300/914 CFRP, Compos. Sci. Technol. 60 (3) (Feb. 2000) 391-401.

[9] E. Wu, K. Shyu, Response of composite laminates to contact loads and relationship to Low-Velocity impact, J. Compos. Mater. 27 (15) (Dec. 1993) 1443-1464.
[10] E.A. Abdallah, C. Bouvet, S. Rivallant, B. Broll, J. Barrau, Experimental analysis of damage creation and permanent indentation on highly oriented plates, Compos. Sci. Technol. 69 (7-8) (June 2009) 1238-1245.

[11] C. Breen, F. Guild, M. Pavier, Impact of thick CFRP laminates: the effect of impact velocity, Compos. Part A Appl. Sci. Manuf. 36 (2) (Feb. 2005) 205-211.

[12] A.L. Highsmith, A Study of the Use of Contact Loading to Simulate Low Velocity Impact, Technical report (Jan. 1997).

[13] Y.S. Kwon, B.V. Sankar, Indentation-flexure and low-velocity impact damage in graphite epoxy laminates, J. Compos. Technol. Res. 0884-6804, 15 (2) (Jan. 1993) 101-111, http://dx.doi.org/10.1520/CTR10361J.

[14] P.A. Lagace, J.E. Williamson, P.W. Tsang, E. Wolf, S. Thomas, A preliminary proposition for a test method to measure (impact) damage resistance, J. Reinf. Plastics Compos. 12 (5) (1993) 584-601.

[15] A.T. Nettles, A.J. Hodge, The Impact Response of Carbon/Epoxy Laminates (Center Director's Discretionary Fund, Project No. 94-13), Technical report (Nov. 1997).

[16] F. Aymerich, P. Priolo, D. Vacca, Static loading and low-velocity impact characterization of graphite/PEEK laminates, International Conference on Advanced Composites(ICAC 98), Hurghada, Egypt, 1998, pp. 519-528.

[17] ASTM International ASTM standard D7136, Measuring the Damage Resistance of a Fiber-reinforced Polymer Matrix Composite to a Drop-weight Impact Event, Technical report (2005) West Conshohocken, PA, 2005.

[18] R. Olsson, Mass criterion for wave controlled impact response of composite plates, Compos. Part A Appl. Sci. Manuf. 31 (8) (Aug. 2000) 879-887.

[19] W.C. Jackson, C.C. Poe, The use of impact force as a scale parameter for the impact response of composite laminates, J. Compos. Technol. Res. 15 (4) (1993) 282-289.

[20] Z. Wang, Y. Xia, Experimental evaluation of the strength distribution of fibers under high strain rates by bimodal weibull distribution, Compos. Sci. Technol. 57 (12) (Jan. 1998) 1599-1607.

[21] I. Benaceur, R. Othman, P. Guegan, A. Dhieb, F. Damek, Sensitivity of the flow stress of nylon 6 and nylon 66 to strain-rate, Int. J. Mod. Phys. B 22 (09n11) (Apr. 2008) 1249-1254.

[22] G. Shan, W. Yang, M.-b. Yang, B.-h. Xie, J.-m. Feng, Q. Fu, Effect of temperature and strain rate on the tensile deformation of polyamide 6, Polymer 48 (10) (May 2007) 2958-2968.

[23] A. Gilat, R.K. Goldberg, G.D. Roberts, Strain Rate Sensitivity of Epoxy Resin in Tensile and Shear Loading, Technical report (Mar. 2005). 